\title{
Crustal Velocity Anomalies in Costa Rica from Ambient Noise Tomography

\author{
E. Nuñez, ${ }^{1,2,3}$ (D) M. Schimmel, ${ }^{1}$ (D) D. Stich, ${ }^{2,4}$ (D) and A. Iglesias ${ }^{1,5}$ (D)
}

\begin{abstract}
We derive group velocity maps for crustal Rayleigh waves across Costa Rica and corresponding 3-D shear-wave velocity structure from ambient noise cross-correlations between 56 seismic broadband stations. The daily inter-station cross-correlations for the period 2010-2015 of 56 seismic broadband stations are stacked and analysed to warrant a robust extraction of empirical Green's functions which then are used to measure fundamental mode Rayleigh wave group velocities. Rayleigh wave dispersion curves show consistent patterns within the different geological domains in Costa Rica. Dispersion curves were evaluated in the microseism band from 5- to 17-s period and inverted for group velocity maps using iterative nonlinear travel time tomography. The group velocities at each grid point were inverted for 1-D profiles using a non-linear simulated annealing approach, and transformed into the 3-D velocity structure. The final tomographic model shows clearly the main velocity anomalies associated with tectonic and volcanic activity in Costa Rica. Three localized negative velocity anomalies are seen at all periods (5-17 s) consistent with deep-routed crustal-scale magmatic systems located beneath the Rincón de la Vieja-Miravalles, Arenal-Poás and Turrialba-Irazú volcanic systems, that showed activity over the last 100 years. High velocities can be found beneath the Talamanca arc in southeastern Costa Rica, where active volcanism stopped in the late Miocene. Significant along-strike variations in the morphology of the subducting Cocos plate are imaged consistently by velocity variations in the forearc.
\end{abstract}

Key words: Ambient seismic noise, cross-correlations, crustal structure, rayleigh-wave dispersion, 3-D surface wave tomography, Costa Rica.

Electronic supplementary material The online version of this article (https://doi.org/10.1007/s00024-019-02315-z) contains supplementary material, which is available to authorized users.

1 Institut de Ciències de la Terra "Jaume Almera", CSIC, 08028 Barcelona, Spain. E-mail: evena17@gmail.com

2 Instituto Andaluz de Geofísica, Universidad de Granada, 18071 Granada, Spain.

3 Volcanological and Seismological Observatory of Costa Rica, Universidad Nacional (OVSICORI-UNA), Heredia, Costa Rica.

4 Departamento de Física Teórica y del Cosmos, Universidad de Granada, 18071 Granada, Spain.

5 Instituto de Geofísica, Universidad Nacional Autónoma de México, Mexico City, Mexico.

\section{Introduction}

Costa Rica is located along the narrow part of the Central American Isthmus between Nicaragua and Panamá. It is characterized by intense tectonic and volcanic activity. The principal driving mechanism for tectonics, volcanism and high topography of Costa Rica is the active subduction of the Cocos plate beneath the Caribbean and Panama plates at the Pacific margin of the country. Subduction-related volcanism from the volcanic arc of Costa Rica (Carr 1984), which extends from the North to the central part of the country, including three large volcanoes that are currently erupting: Rincón de la Vieja, Poás, and Turrialba, and three more volcanoes that were active since the 20th century, the Miravalles, Arenal and Irazú volcanoes (e.g. Global Volcanism Program 2013).

Previous seismic and gravimetric studies in Costa Rica (Protti et al. 1994, 1995; Husen et al. 2003; DeShon 2003; DeShon et al. 2006; Arroyo et al. 2009; Dinc et al. 2010; Dzierma et al. 2010; Lücke et al. 2010; Alfaro et al. 2018) constrain the heterogeneity of the lithospheric structure and show significant variability along strike of the subduction zone and, of the upper and lower crust beneath the volcanic arc and the Cordillera de Talamanca (CTA) in Costa Rica. Beneath the volcanic arc, low-velocity anomalies in the upper and lower crust were related to deformation, fluid release, and hydration (Dinc et al. 2010), while high velocity anomalies were found in the CTA (Husen et al. 2003) and in the forearc shallow crust (Protti et al. 1995). However, despite efforts to characterize the structure beneath Costa Rica, some of these studies do not cover all Costa Rica or have a poor resolution in the shallow crust. 
(a)

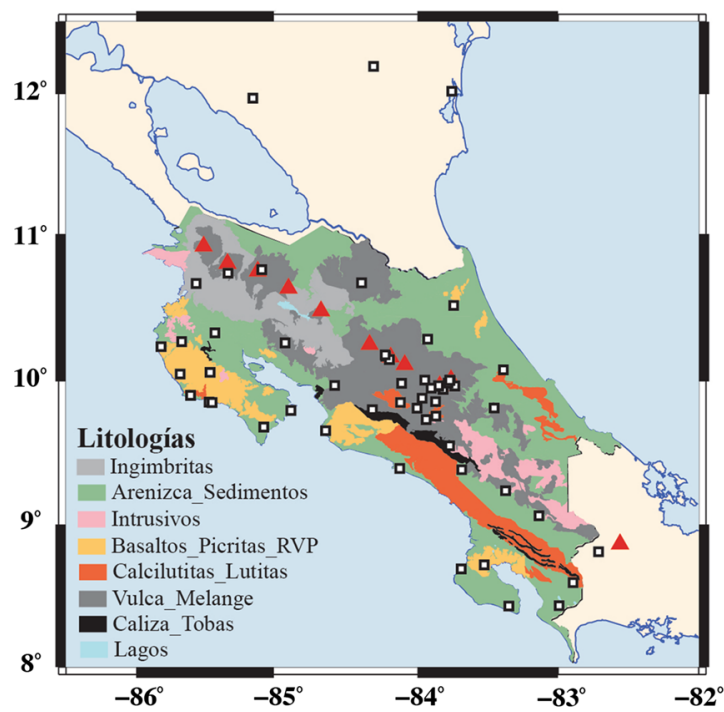

(b)

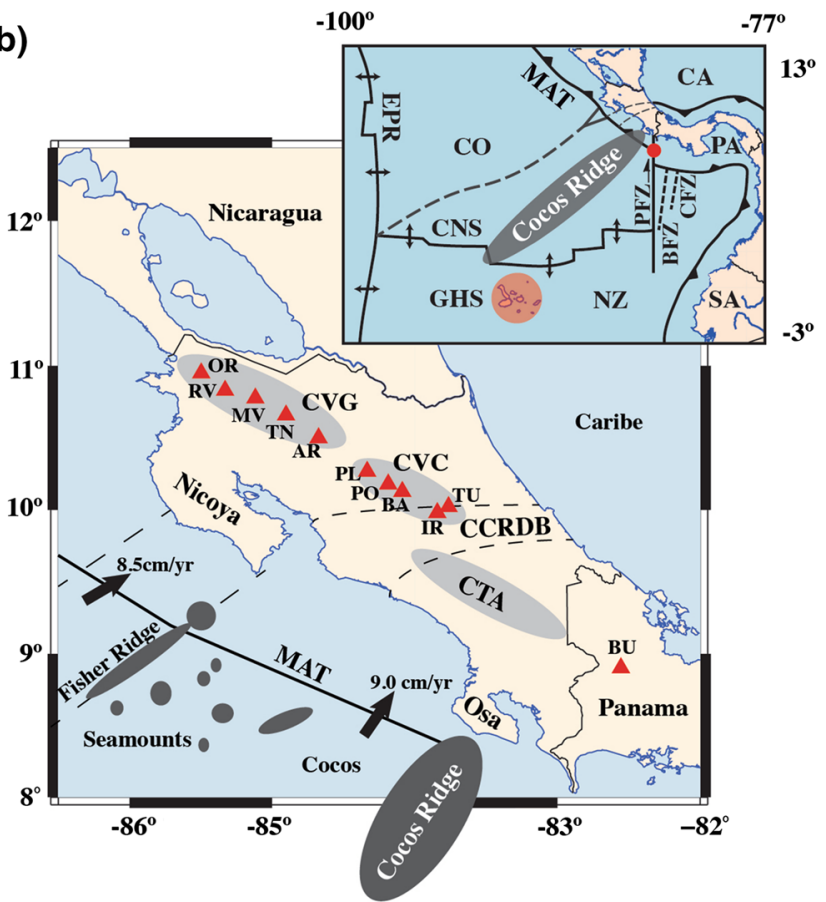

Figure 1

a Simplified geological map of Costa Rica (modified from Tournon and Alvarado 1997) and (b) main tectonic features (modified from Husen et al. 2003). White squares and red triangles mark the location of seismic stations and volcanoes, respectively. The different provinces are: MAT Middle American Trench, CCRDB Central Costa Rica Deformed Belt, CVG Cordillera Volcánica Guanacaste, CVC Cordillera Volcánica Central, CTA Cordillera de Talamanca, HGS Galapagos hot spot, CA Caribbean plate, CO Cocos plate, NZ Nazca plate, EPR East Pacific Rise, $C N S$ Nazca-Cocos Spreading centre, $P F Z$ Panama fracture zone, BFZ Bolboa fracture zone, $C F Z$ Coiba fracture zone. The volcanoes are: $O R$ Orosi, $R V$ Rincón de la Vieja, $M V$ Miravalles, $T N$ Teneorio, $A R$ Arenal, $P L$ Platanar, $P O$ Poas, $B A$ Barba, $I R$ Irazu, $T U$ Turrialba, $B U$ Baru

The seismic network density (Fig. 1a) and the geographic setting of Costa Rica between the Pacific Ocean and the Caribbean Sea, and the narrow shape of the country assures a broad azimuthal coverage with potential ocean noise sources. A beam forming analysis by Harmon et al. (2008) using the TUCAN array in NW Costa Rica and SW Nicaragua confirms the broad distribution of source azimuths for the microseisms band that constitutes the main frequency band for our study. All this provides good conditions to perform ambient noise tomography (ANT) for Costa Rica.

The main objective in this study is to obtain a shear-wave velocity model of the shallow crust beneath Costa Rica. To achieve this goal we invert high-resolution tomographic images for fundamental mode Rayleigh wave group velocities obtained from the inversion of measured dispersion curves extracted from the estimation of empirical Green's functions (EGF). The EGFs are based on stacks of daily crosscorrelations of continuous seismic noise recordings of 56 broadband stations from January 2010 to December 2015.

\section{Geology and Tectonic Setting}

The tectonics of Costa Rica are mainly controlled by the subduction of the Cocos Plate beneath the Caribbean and Panama plates along the south margin of the Mesoamerican Trench (MAT) in the Pacific coast, with NNE-direction and a convergence rate of 85-90 mm/yr (Fig. 1b) (DeMets et al. 2010). The convergent contact between the Panama plate and Caribbean plate in southeastern Costa Rica is known as the Northern Panama Deformed Belt 
(NPDB), where the Caribbean plate subducts beneath the Panama plate, at a rate of $\sim 7+-2 \mathrm{~mm} / \mathrm{yr}$ (Stefan et al. 1988; Silver et al. 1990). This belt extends from the Uraba Gulf in Colombia to Puerto Limon in the Caribbean coast of Costa Rica and parallel to the Caribbean Panama coast. A diffuse and wide zone of active faulting across central Costa Rica, the Central Costa Rica Deformed Belt (CCRDB) (Fig. 1b) forms the western boundary with the Panama plate (Fan et al. 1993; Goes et al. 1993; Marshall et al. 2000).

As inferred from magnetic anomalies (Werner et al. 1999, Barckhausen et al. 2001), the young oceanic crust of the Cocos plate is produced simultaneously at the $\sim \mathrm{N}-\mathrm{S}$ trending East Pacific Rise (EPR) and the $\sim \mathrm{E}-\mathrm{W}$ trending Nazca-Cocos Spreading centre (CNS), giving rise to a complex pattern of anomalies and variable age of the lithosphere that is subducted at the MAT. The seafloor shows important morphological changes, visible on the bathymetry of the region. The spatial distributions of the asperities towards the south and the seismic activity along the MAT have shown that the subduction of the Cocos plate can be subdivided in three segments (Morell 2015). The segment at the Nicoya Peninsula in northwestern Costa Rica is characterized by smooth seafloor topography, an age of $24 \mathrm{Ma}$ and a steep dip of the subduction zone of about $80^{\circ}$ (Protti et al. 1994, 1995; Werner et al. 1999; Barckhausen et al. 2001) (Fig. 1b). In the central part, a rather abrupt transition is observed, with a bathymetry dominated by seamounts with up to $\sim 2 \mathrm{~km}$ elevation (Bilek et al. 2003; Wang and Bilek 2014). This segment has a variable age of 14-19 Ma and dip of about $60^{\circ}$ (Protti et al. 1994, 1995, 2001). Towards the south, the most prominent bathymetric feature in the Cocos plate is the $\sim 1000 \mathrm{~km}$ long Cocos Ridge, a maximum crustal thickness of $\sim 19 \mathrm{~km}$ (Sallarès et al. 2003) and with an age of $\sim 15 \mathrm{Ma}$ (Werner et al. 1999; Barckhausen et al. 2001), in front of the Osa Peninsula in southeastern Costa Rica (Fig. 1b). The Cocos Ridge, as well as the adjacent seamount segment, is the track of the Galapagos hot spot on the Cocos plate.

South of the Osa Peninsula, the Cocos plate subduction links with the Nazca plate at the Panama fracture zone (PFZ), the PFZ is part of the border between both plates. The PFZ originates east of the CNS, as an ocean fault with north direction and transtensional motion between the two oceanic plates (Morell 2015). In this zone, the Cocos, Nazca and Panama plates conform the Panama triple junction and the MAT disappears towards the southeast, joining the PFZ and the boundary between the Panama and Nazca plate.

Costa Rica is divided into three main mountain ranges (Fig. 1b), the Cordillera de Talamanca (CTA) to the south of the Costa Rica is a mountainous system with the highest elevation of Central America, the Chirripo hill with an altitude of $3820 \mathrm{~m}$ above sea level (Tournon and Alvarado 1997; Alfaro et al. 2018). The presence of igneous rocks and intrusive materials in the CTA (Fig. 1a) shows that it was part of the volcanic arc and that it was active until the late Miocene (Alfaro et al. 2018). Previous studies considered that the subduction of the Cocos ridge produced changes in the tectonics (Montero 2001) and in the geochemistry of the region (Hoernle et al. 2008; Gazel et al. 2009, 2011, 2015). This agrees with the absence of recent volcamism (1 million years or less) in the CTA (Alfaro et al. 2018). In the central part is the Central Volcanic Mountain Range (CVC) and to the north is the Guanacaste Volcanic Mountain Range (CVG), these last two conform the volcanic arc of Costa Rica. It has around 150 volcanoes, three of them, Rincon de la Vieja, Poas and Turrialba, are currently in eruption. Other volcanoes such as Miravalles, Arenal and Irazú have been active during the 20th century according to historical records (Fig. 1b) (Global Volcanism Program 2013).

\section{Data Processing and Analysis}

\subsection{Seismic Stations, Data Pre-Processing, and Noise Cross-Correlations}

The noise processing, from continuous vertical component broadband data to estimated Empirical Green's functions (EGF), incorporates a total of 56 seismic stations (Fig. 1a). The vast majority of these stations are permanent and belong to the Observatorio Vulcanológico y Sismológico of Costa Rica (OVSICORI-UNA). The Laboratorio Sísmico of Costa Rica 
operates two of the stations. To extend the ray coverage over the study area, we also included data from three stations in Nicaragua and one in Panama, whose data have been downloaded from the Incorporated Research Institutions for Seismology (IRIS; http://ds.iris.edu/ds/). We process 39,439 daily continuous recordings with at least 3 months per station and daily data segments with duration greater than $22 \mathrm{~h}$ for the period between January 2010 and December 2015. The mean and trend of the data were removed and the effect of the instrument response was corrected to obtain ground velocity. Polarity reversals were checked and corrected after analysing five teleseismic events. Lastly, the continuous recordings were band-pass filtered between 0.02 and $0.33 \mathrm{~Hz}$.

In the following, we utilized the MSNoise program package by Lecocq et al. (2014) to normalize the data (one-bit and spectral whitening) and to finally compute daily cross-correlations for all station pairs with inter-station distances between 36 and $445 \mathrm{~km}$ and time lags between - 250 and $250 \mathrm{~s}$. This minimum distance represents three times the wavelength for a period of $5 \mathrm{~s}$ and group velocity of $2.4 \mathrm{~km} / \mathrm{s}$.

\subsection{Cross-Correlation Stacks and Convergence}

The daily cross-correlations were stacked using a linear stack as well as a time-frequency phase weighted stack tf-PWS (Schimmel and Gallart 2007; Schimmel et al. 2011). The latter method employs the S-transform (Stockwell et al. 1996) to convert the cross-correlograms into the time-frequency domain to finally use the phase-coherence to attenuate incoherent signals in the time-frequency domain during stacking. Transforms to the wavelet domain can be used similarily (Ventosa et al. 2017). The phase-coherence is obtained from the instantaneous phases of analytic signals in full analogy to the time-domain phase weighted stacking (PWS, Schimmel and Paulssen 1997). The waveform similarity is measured by the closeness of the instantaneous phases, that are exactly the same for identical waveforms, and is used as weight to attenuate phase-incoherent signals. This procedure is often used to increase the signal-to-noise ratio (SNR)
(Haned et al. 2015; Poveda et al. 2018, among others).

The EGFs are finally obtained after stacking all daily cross-correlations per station pair. Considering all station pairs with inter-station distance larger than $36 \mathrm{~km}$ we acquire a total of 1484 EGFs (a representative selection shown in Fig. 2). Most of our EGFs are clearly asymmetric, which is a consequence of the spatially asymmetric noise source distribution. For the tomography we consider the symmetric empirical Green's function (SEGF) estimated by averaging the time-reversed acausal (negative lag-time) parts and the respective causal (positive lag-time) parts of the cross-correlations.

The convergence of the cross-correlations to a stable noise response is a useful quality indicator: although this is not a guarantee of closeness to a Green's function, it indicates that the extracted waveforms will not change anymore when adding additional noise data. The amount of data needed to achieve a robust noise response depends on factors as frequency, inter-station distance, and relative position to the noise sources, among others.

We analysed the waveform convergence for different station pairs using as reference the waveforms obtained after stacking all the daily crosscorrelations. Figure 3 shows two examples for

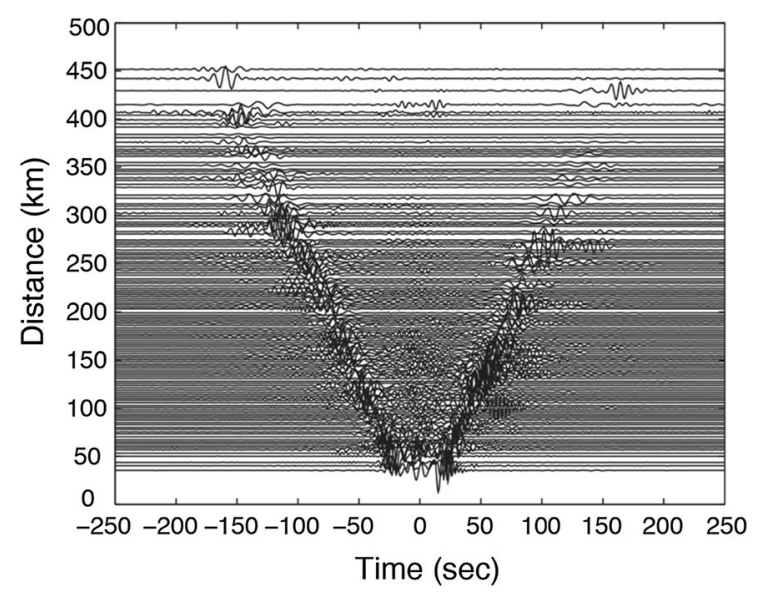

Figure 2

Representative selection of empirical Green's functions (EGFs) estimated as function of inter-station distance. EGFs were obtained by stacking daily cross-correlations for each station pair and up to 6 years of vertical component ambient noise recordings. The visible signals are fundamental mode Rayleigh waves 

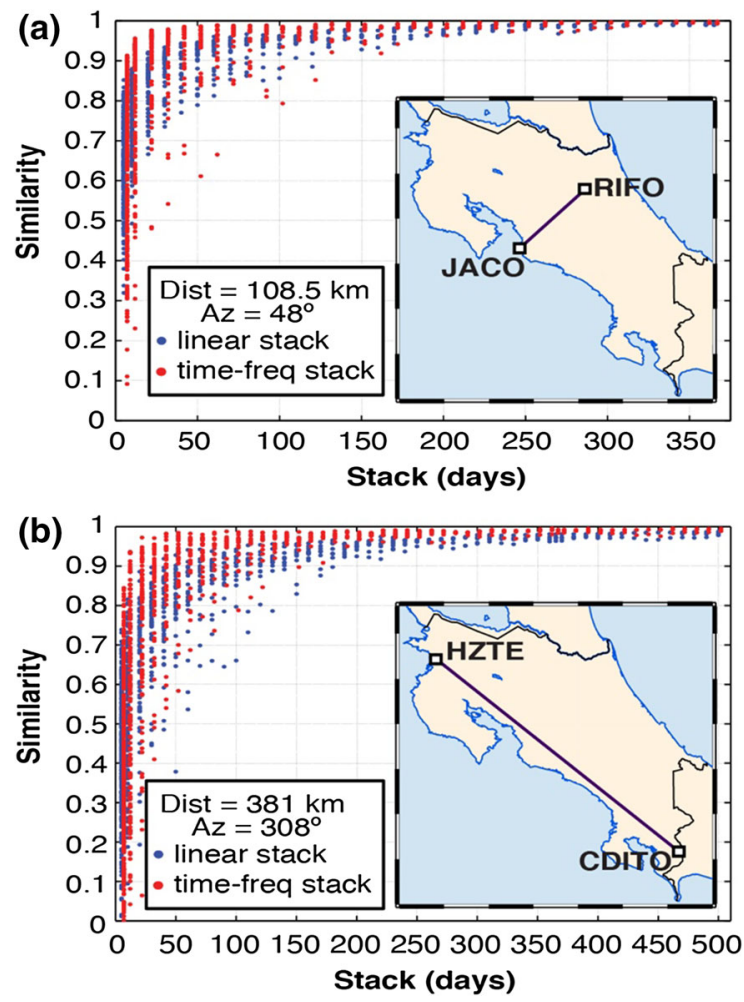

Figure 3

Waveform convergence to the EGF obtained from stacking 6 years of noise cross-correlations (a) for station pair JACO-RIFO (in direction perpendicular to the coast) and (b) for station pair HZTECDITO (parallel to the coast). The daily noise cross-correlations are computed using the classical correlation method and are stacked using the linear (blue dots) and tf-PWS (red dots) approach. The convergence is measured through waveform similarity by determining the classical cross-correlation at zero-lag

different directions, i.e., perpendicular to the coastlines of Costa Rica (SE-NW) and parallel to the coast (SW-NE). We further compare different stacking approaches, i.e., a linear stacking (blue dots) and a tfPWS (red dots). The waveform similarity is quantified as their zero-lag cross correlation. The daily cross-correlations have been selected randomly. Convergence is clearly faster when using tf-PWS, compared to a linear stack. This confirms the benefits of attenuating incoherent signals with tf-PWS during the stacking. We also observe that about 1 year of noise recordings are required to achieve a stable response for station pairs aligned parallel to the coast. Station pairs perpendicular to the coast require less data, 250 days for this example, due to their closer alignment with the propagation direction of ocean- generated noise. Further examples for other station pairs are shown in the supplementary material (Fig. S1).

\subsection{Group Velocity Assessment}

We measure the Rayleigh wave group velocities in the extracted EGFs by tracking the group arrivals in the time-frequency domain. To this end, the EGFs were transformed using the S-transform (Stockwell et al. 1996). The group arrivals were found as energy maxima at a given frequency and the group velocity was obtained using the inter-station distance and group arrival time. This analysis was performed employing an early version of the approach presented in Schimmel et al. (2017) without data resampling. Further, we considered an adaptive frequency band where the minimum frequency corresponds to the wavelength of one-third the inter-station distance and where the maximum frequency is fixed to $0.33 \mathrm{~Hz}$. All dispersion curves were analysed manually and frequency bands were further adjusted to keep the dispersion curves free of ambiguous signals. Out of 1484 computed EGFs, only 780 dispersion curves (52\%) passed the visual quality control and were retained for the determination of the group velocity maps. Through the visual control we basically identified station pairs that provided an unambiguous dispersion curve within a realistic group velocity window. Figure $4 a, b$, d, e show the EGFs and corresponding dispersion curves for two station pairs (parallel and perpendicular to the coast) and typical data quality.

In analogy to the EGF convergence tests we also determined the robustness of the dispersion curves as function of frequency and number of daily crosscorrelations for several station pairs. Figure $4 \mathrm{c}, \mathrm{f}$ shows two examples. Plotted are the mean of absolute values of relative differences between a reference dispersion curve and dispersion curves obtained for six subsidiary data sets as function frequency and number of daily cross-correlations in the subsidiary data sets. The reference waveforms (Fig. 4a, d) and corresponding reference dispersion curves (Fig. 4b, e) were obtained using all available data, while the subsidiary data sets were constructed through a random selection of daily noise cross-correlations 
(a)

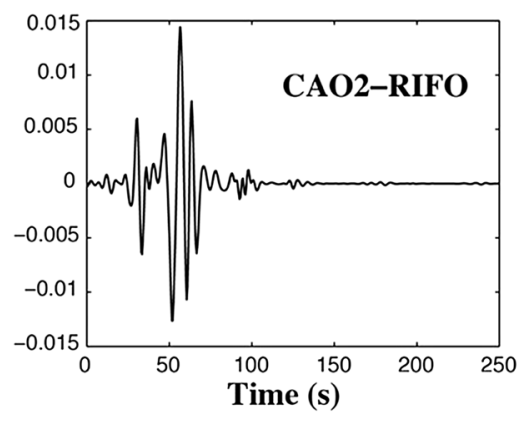

(d)

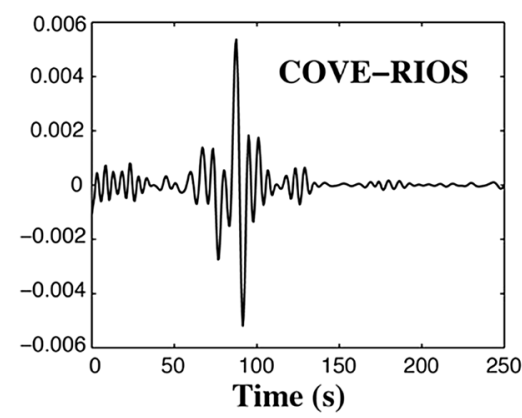

(b)

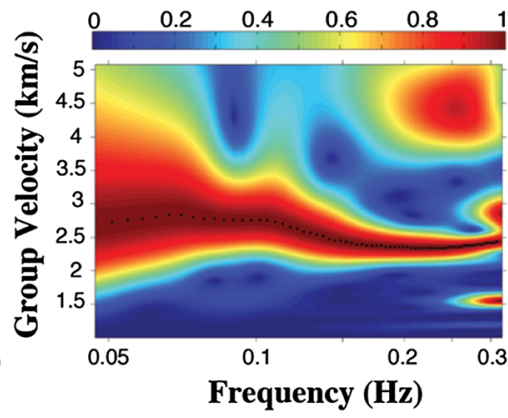

(e)

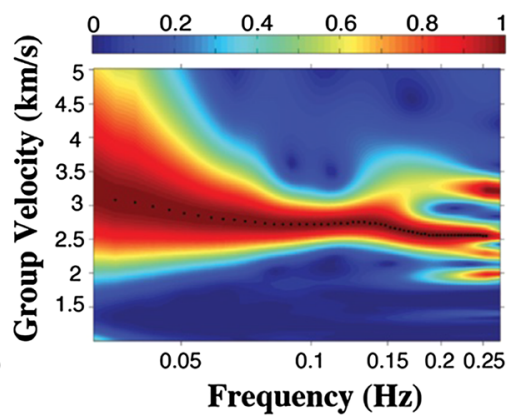

(c)

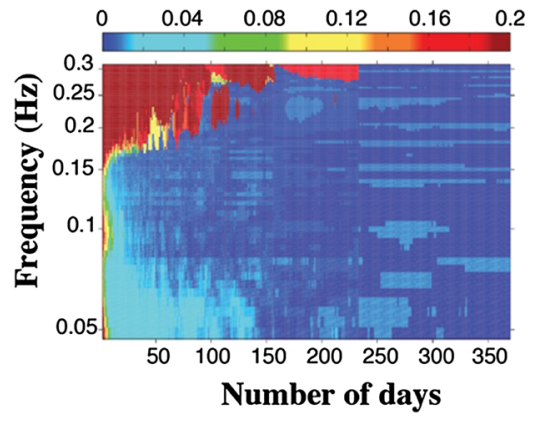

(f)

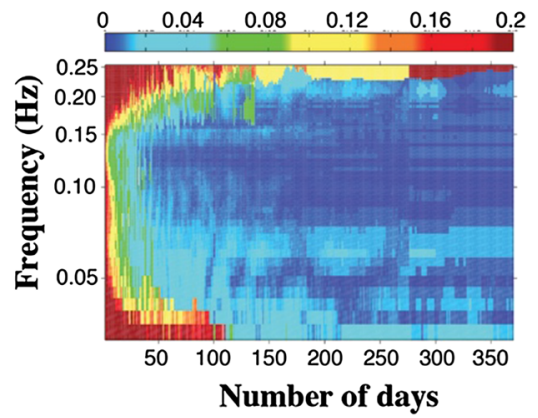

Figure 4

a EGF for station pair CAO2-RIFO (perpendicular to the coast). b Rayleigh wave group velocity spectrum for the waveform shown in (a). Amplitudes are normalized to unity for each frequency to track the group arrival. c Frequency-dependent convergence to the dispersion curve obtained from 6 years of data (waveform shown in a) as function of number of daily noise-correlations. Contoured are the mean of the absolute relative differences between the dispersion curves measured for the partial and full data sets. d-f Same as (a-c), but for station pair COVE-RIOS (parallel to the coast)

per year. The random sampling is used to attenuate seasonal effects and the averaging over different years to further stabilize the group velocity differences. It can be seen from Fig. 4c, $\mathrm{f}$ that the dispersion curves are quite stable at mid-range frequencies $(0.05-0.15 \mathrm{~Hz})$ after a couple of months, while much more data is needed to obtain stable dispersion curves at both ends of our considered frequency band. Noise sources below the primary microseisms $(<0.05 \mathrm{~Hz})$ are less energetic which may explain the slower convergence. Near the high frequency limit $(>0.15 \mathrm{~Hz})$, less energy, a heterogeneous source distribution and other interfering signals may explain the high variability in the dispersion measurements.

To further assess the consistency and quality of our data, we test whether the measured dispersion curves show similar characteristics for different paths within the same geological unit. For this purpose, we delimit four larger areas with similar geology (Fig. 5, lower panel) and plot the corresponding dispersion curves for stations within these areas with the same colour code (Fig. 5, upper panel). The black dots mark the average Rayleigh wave velocities from a 1-D model as determined in a previous study by Husen et al. (2003) and Quintero and Kissling (2001) and hereafter labelled as CR-1D. It is visible from Fig. 5 that our measured velocity curves cluster into groups following the different geological regimes, and that our measurements roughly follow the average model CR-1D, validating the performance of this model for Rayleigh wave propagation. The differences with the CR-1D model, as well as the variability of dispersion curves within each group, as well as around the CR-1D model, are within range of measurement errors and the imprint of three-dimensional (3-D) wave speed heterogeneity over the study area. 


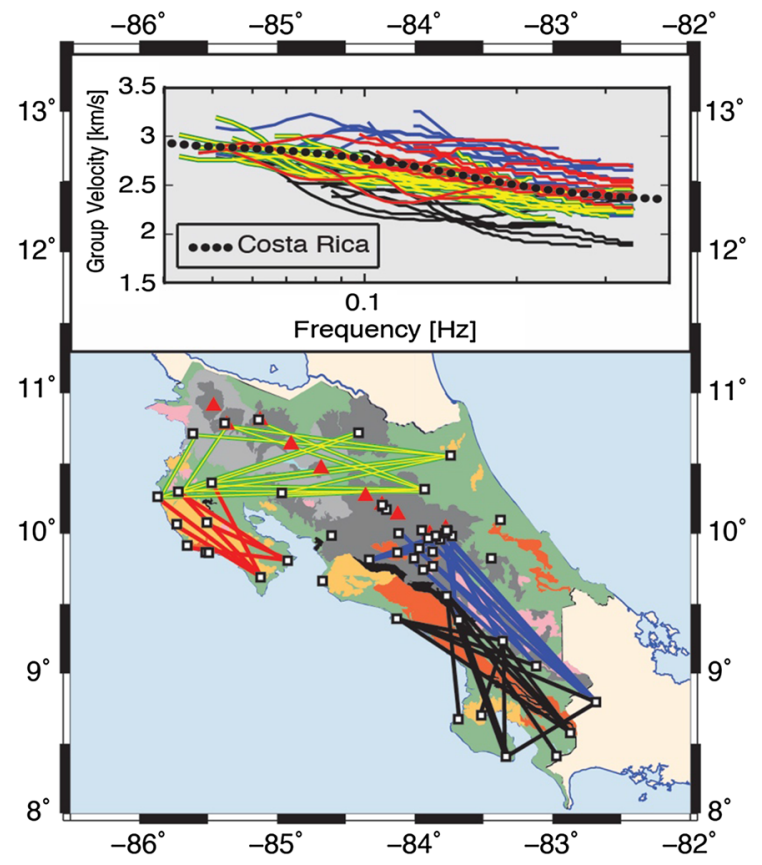

Figure 5

Upper panel: Measured dispersion curves for different inter-station paths, colour coded according to their geological domains (lower panel). The red, black, blue and green-yellow lines correspond to paths from Nicoya, Osa, Cordillera de Talamanca and Cordillera Volcánica zone, respectively. Black dots mark the dispersion curve for the average 1-D Costa Rica velocity model obtained by Husen et al. (2003) and Quintero and Kissling (2001)

\section{Group Velocity Inversion}

So far we have shown the consistency and quality of our dispersion measurements which we now use to determine the seismic velocity structure beneath
Costa Rica. We first consider group velocity maps which then are inverted into 3-D velocity structure. To obtain group-velocity maps we applied the Fast Marching Surface Tomography (FMST) method (Rawlinson 2005). This approach follows an iterative nonlinear inversion scheme that takes advantage of the Fast Marching Method (FMM) (Sethian $1996,1999,2001)$ to solve the forward problem of each iteration, i.e. to newly determine the travel times in the updated 2-D velocity model. FMM is an eikonal solver, which uses finite differences to find the wavefronts from the phase delays. One of the advantages over ray tracing is that FMM provides the minimum (or maximum) travel-time which one may miss with ray tracing in the presence of multipathing. FMM supplies stable and robust solutions in heterogeneous media (Rawlinson and Sambridge 2004). The 2-D model is parameterized by $45 \times 45$ velocity nodes, which are regularly spaced by $0.1 \mathrm{deg}$ in latitude and longitude. Further, a constant initial velocity was taken to start the inversion. The covariance matrices were assumed to be constant which means that we did not weight differently individual measurements or model parameters.

\subsection{Regularization Parameters}

The regularization parameters were chosen after repeated determination of the characteristically L-shaped trade-off curves for fixed damping $\varepsilon$ or smoothing $\eta$ (Fig. 6), following Rawlinson et al. (a)

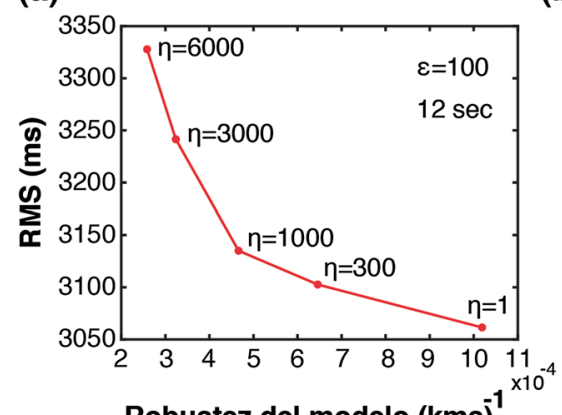

(b)

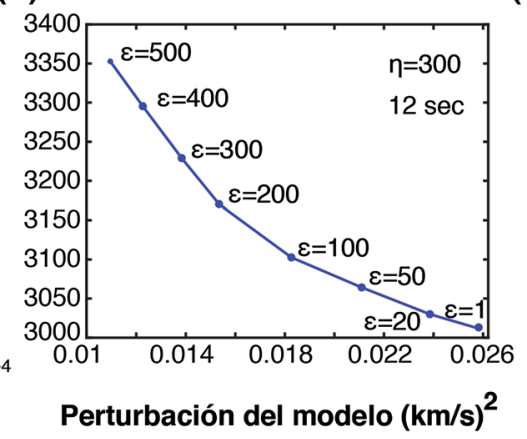

(c)

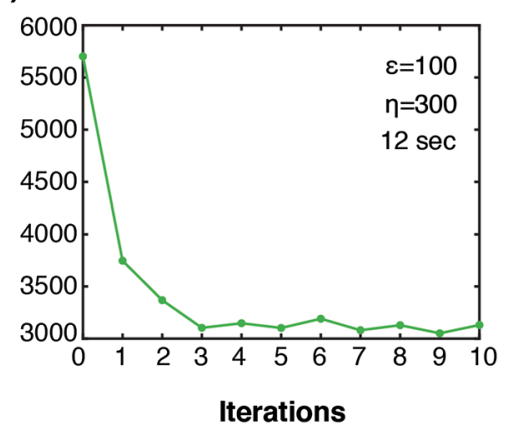

Figure 6

Trade-off curves for the Rayleigh wave group velocity inversion at $12 \mathrm{~s}$ period. a RMS data-misfit with model roughness for damping factor $\varepsilon=100$. b RMS misfit with model variance for smoothing factor $\eta=300$. $\mathbf{c}$ RMS data-misfit as function of number of iterations for damping $\varepsilon=100$ and smoothing $\eta=300$. The inversion converges after 3 iterations 

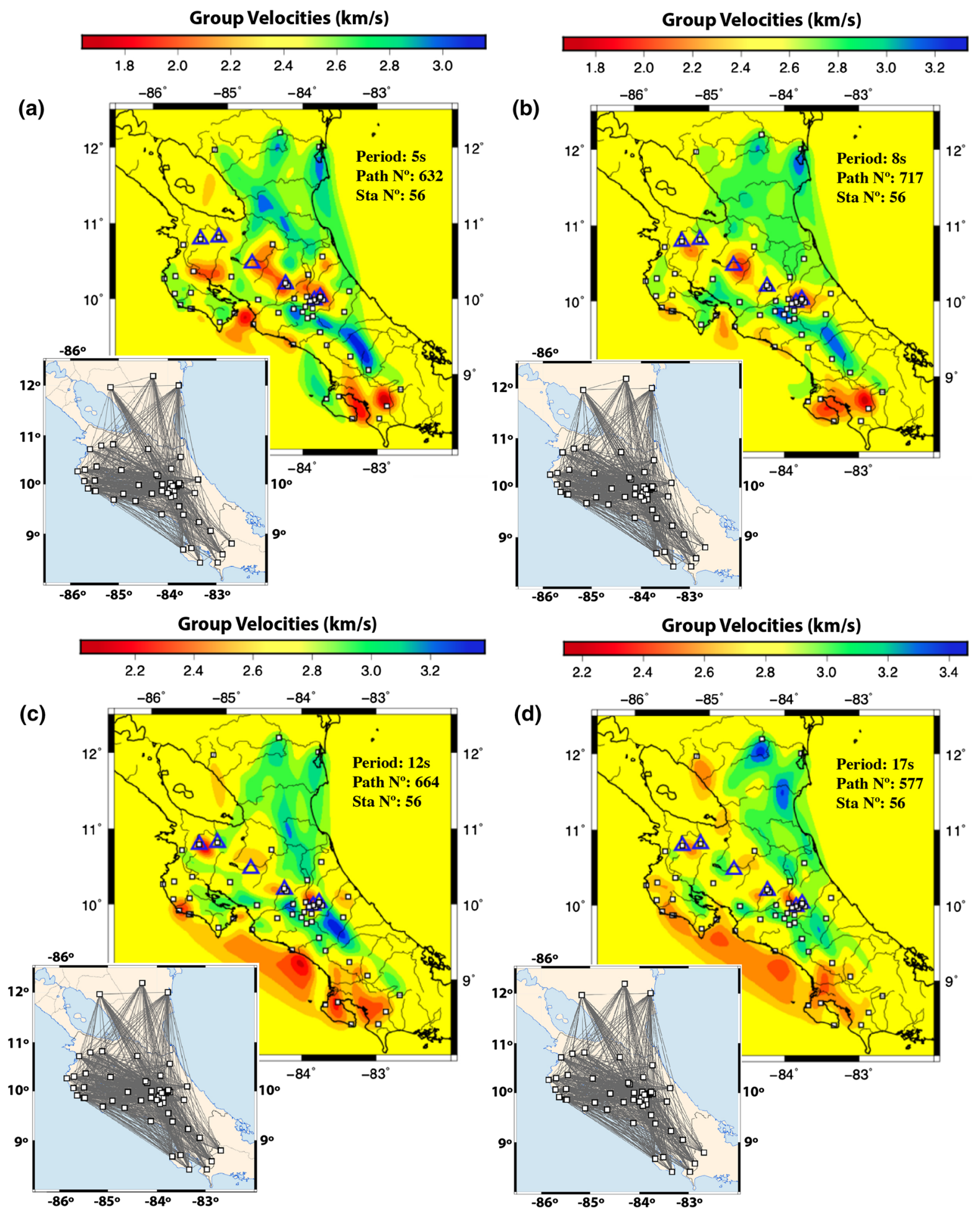

(2006). In a first step, we started from a fixed $\varepsilon=1$ and explored the trade-off curve by varying $\eta$. $\eta=300$ was chosen as compromise between data

misfit reduction and model roughness. In a next step $\eta$ was fixed to 300 while $\varepsilon$ was varied. Here, $\varepsilon=100$ was chosen as compromise between data misfit and 
Figure 7

Group-velocity maps for periods of $5 \mathrm{~s}(\mathbf{a}), 8 \mathrm{~s} \mathrm{(b),} 12 \mathrm{~s}(\mathbf{c})$ and $17 \mathrm{~s}$ (d). The respective ray path coverage is shown to the lower left of each figure. White squares and blue triangles mark the seismic stations and the active volcanoes of the last 100 years, respectively. Variable color scale is used for different periods and depths, to ensure that the Costa Rica 1D model corresponds to yellow color (no anomaly)

model variance. Now the first step was repeated using $\varepsilon=100$ which confirmed $\eta=300$ as a reasonable value. Figure $6 \mathrm{a}, \mathrm{b}$ show the trade-off curves for $\varepsilon=100$ and $\eta=300$ for $T=12 \mathrm{~s}$ period and 3 iterations. The data misfit as function of number of iterations is shown in Fig. $6 \mathrm{c}$ for $\varepsilon=100, \eta=300$, and $\mathrm{T}=12 \mathrm{~s}$. It is seen from Fig. $6 \mathrm{c}$ that the inversion converges quickly after three iterations. The obtained group velocity maps for selected periods between 5 and $17 \mathrm{~s}$ are shown in Figs. 7 and S2, and are discussed further below. The final group velocity maps can explain the data variance reduces by about $77.5 \%$.

\subsection{Group-Velocity Maps}

Figures 7 and S2 show the final group velocity maps for selected periods between 5 and $17 \mathrm{~s}$. The group velocity maps are accompanied with the corresponding ray coverage. It can be seen that the ray coverage is high in the centre of Costa Rica, including the volcanic arc, the Cordillera de Talamanca (CTA), Nicoya and Osa peninsula, and the west coast of Costa Rica (Fig. 1b). Unfortunately, the Caribbean Coast is not covered by crossing rays due to the lack of stations to the southeast. Slower and faster than average velocities are presented with warmer and cooler colours. Yellow is assigned to the constant velocity used to initiate the group velocity inversions. The resolution of these maps is discussed in the following section.

The results of the group velocity maps (Figs. 7 and S2) show three separate low-velocity structures in the volcanic arc, which may be associated with deep hydrothermal systems, magma chambers or their feeding systems (Dzierma et al. 2010; Lücke et al. 2010). These anomalies are particularly clear in the group velocity map at $8 \mathrm{~s}$ period. Other important low-velocity anomalies are observed along the Pacific coast and likely related to the subduction of the Cocos Plate. The elongation of these anomalies is mostly parallel to the subduction front, independent from the dominant SW-NE ray directions. Inspite of the lack of high resolution, the gross group velocity variations along the Pacific margin reproduce the changes in seafloor morphology in front of the trench (Morell 2015): The smooth segment that subducts beneath the Nicoya Peninsula is associated with relatively high velocities, while Cocos Ridge subduction beneath the Osa Peninsula is seen as significantly lower velocities (e.g. Figure 8b), presumably related to higher fluid release. The intermediate, seamount segment is associated with smaller anomalies.

Additionally, we observe high-velocity anomalies in the south and north of the volcanic arc, over a broad period range (5-17 s). To the north, the high velocities seem to include the entire southeastern part of Nicaragua, although the resolution is relatively low (see Sect. 4.3). The higher than average velocities are likely related to the Yolania Mountains, which are formed by dense Cenozoic volcanic rocks (Bunduschuh and Alvarado 2007). The high-velocities to the south of the volcanic arc coincide with the Talamanca Mountain Range, which matches the velocity trends expected from the geological structure.

\subsection{Group-Velocity Resolution Analysis}

The interpretation of any tomographic image requires knowledge of the resolution. We determine the resolution through synthetic test inversions where the input model is a checkerboard of alternating highand low-velocity anomalies in two dimensions. The checkerboard input models of two different lengthscales are shown in Figs. 8a, c and S3a. The synthetic travel times were computed with the FMM for the ray paths used in each field data inversion. We further randomly contaminated the computed group arrival times with noise of up to $\pm 5 \%$ of the travel time for the test inversion shown in Fig. S3. The added noise causes data inconsistencies that may map into poorly resolved areas. Further, the test inversions use the 

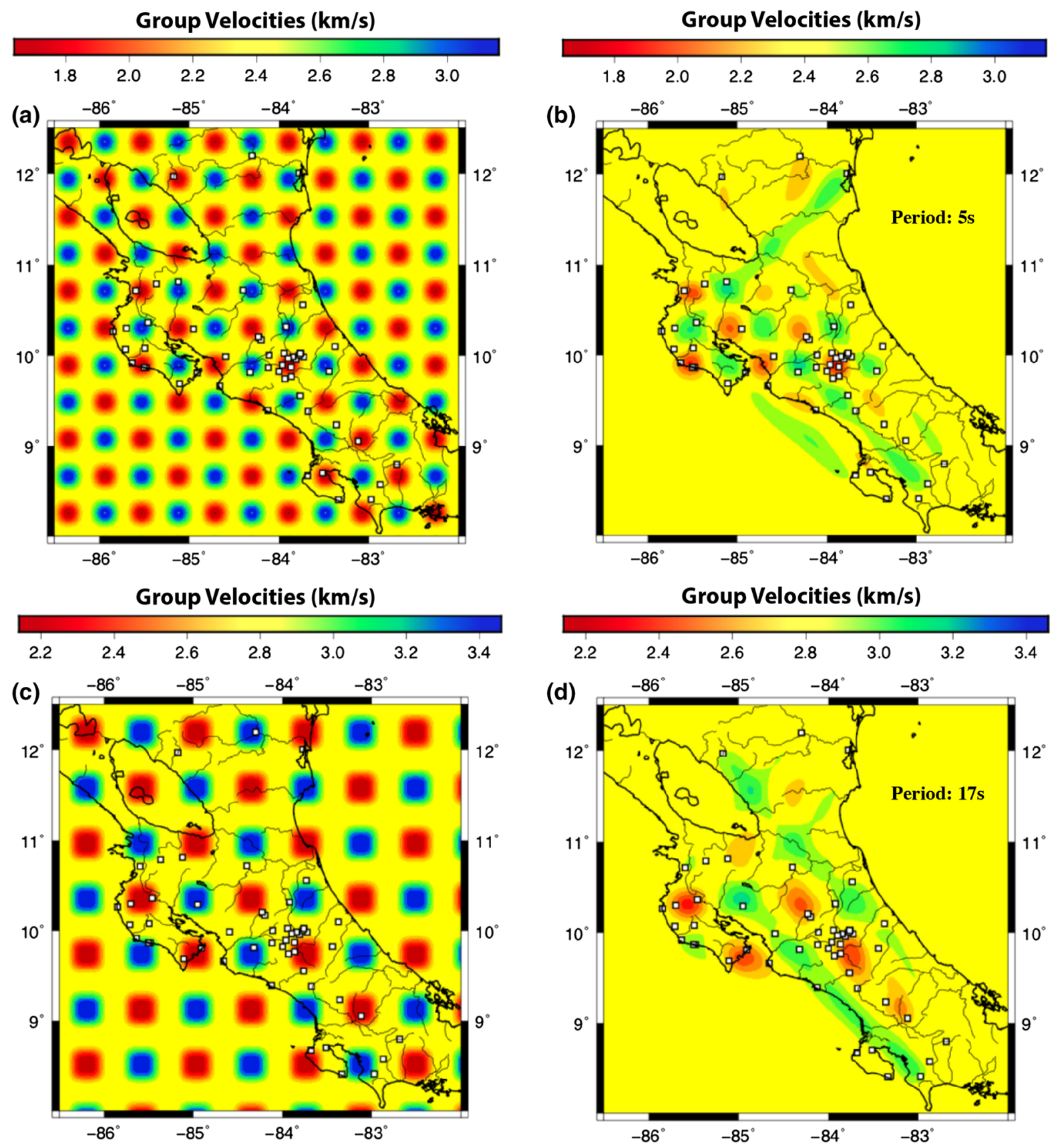

Figure 8

Checkerboard resolution test for group velocities. a Input model and (b) recovery at $7 \mathrm{~s}$. $\mathbf{c}$ Input model and (d) recovery at $17 \mathrm{~s}$ but for more separated and larger anomalies. The same field data configuration and the actual inversion parameters were used. White squares mark station

same regularization parameters as our field data inversions. Figure $8 \mathrm{~b}, \mathrm{~d}$ and Fig. S3b show the recovered models for periods $5 \mathrm{~s}, 17 \mathrm{~s}$ and $7 \mathrm{~s}$, respectively. It can be seen that the inversions underestimate the amplitudes of the anomalies. This is normal and mainly caused by the regularization, 
i.e., through the employed damping and smoothing. Location and extent of the anomalies are well retrieved between 9.6 and $11^{\circ}$ latitude, especially in the centre and west of Costa Rica. To the north and south of this area, one mainly observes elongated anomalies, which tend to reproduce the dominant ray paths and connect the diagonally organized anomalies. Figure S4 shows input and recovery of isolated anomalies which overcome the dependency on the directions of the checkerboard mesh. The recovery (Fig. S4b) confirms the good resolution in the center of Costa Rica, with significant artifacts along the interpreted anomalies.

We also performed field data inversions for subsidiary data sets where we removed all data from an individual station or group of stations (Fig. 9). The corresponding inversion results permit to identify anomalies which are caused by only one station and likely due to some systematic measurement problem. All here identified and interpreted anomalies robustly appear in the group velocity maps. Figure 9c shows an inversion result for $\mathrm{T}=7 \mathrm{~s}$ where we removed all volcanic stations. The number of stations is reduced from 56 to 42 and ray paths are reduced from 712 to 460 in this image. It can be seen that all volcanic arc anomalies are still mapped in the same positions, although with slightly different geometry and amplitudes inherent to the reduced data set and corresponding coverage. The volcanic arc anomalies are therefore robust anomalies that are not solely produced by the volcanic arc stations, but that can be obtained in a similar way from crossing rays alone.

Figure 9d demonstrates the inversion results without stations in the Cordillera de Talamanca (CTA) and stations to the south of Costa Rica. A total of nine stations were removed to perform the inversion for 514 inter-station paths. The higher than average velocities of the central range and Cordillera de Talamanca remain visible as well as the prominent lower than average velocity anomaly at the Pacific coast in the south of Costa Rica. In any case, the gross features of both inversion results resemble well with the anomalies presented in Fig. 9a, b and give us the confidence of interpreting robust features. These last field data inversions further confirm that our group velocity maps are consistent and robust to permit subsequent inversion into a 3-D shear-wave velocity model.

\section{Shear-Wave Velocity Inversion}

To obtain the 3-D shear-wave velocity (Vs) structure, we invert the dispersion curves derived from each grid point of the group velocity maps. The model was parametrized with 20 homogeneous and isotropic layers of $1 \mathrm{~km}$ thickness each. The inversion algorithm finds Vs for each layer, in an interval between 1.8 and $3.5 \mathrm{~km} / \mathrm{s}$. Trying to avoid over parameterization, we assume a Poisson solid $\mathrm{Vp}=$ $\sqrt{3.0} \cdot \mathrm{Vs}$ and density for each layer is computed from the relation (Berteussen 1977) $\rho=0.32 \alpha+0.77$, where $\alpha$ is in $\mathrm{km} / \mathrm{s}$ and $\rho$ in $\mathrm{g} / \mathrm{cm}^{3}$.

For inversion we use an optimized simulated annealing scheme (Iglesias et al. 2001) to minimize E:

$$
E=\sqrt{\sum_{n}\left(U_{i}^{0}-U_{i}^{P}\left(\beta_{1, \ldots, 20}\right)\right)^{2}}
$$

where $\mathrm{U}_{\mathrm{i}}^{0}$ is the group velocity for the $i t h$ period, and $\mathrm{U}_{\mathrm{i}}^{\mathrm{p}}$ is the predicted group velocity for the ith period and depending of the set of $\mathrm{S}$-wave velocities for the 20 layers in our model.

In this scheme, the forward problem (predicted group velocities) is solved using one of the subroutines form the "Computer Programs in Seismology" package (Herrmann 2013). Note that sharp discontinuities cannot be resolved by the inversion of surface wave dispersion curves alone, since the dispersion properties depend on the integration over depths (see group velocity depth kernels in Fig. S5). In consequence, to avoid models with abrupt variations between velocities in adjacent layers, along the inversion, we do not accept perturbed models that break the rule:

$$
\beta_{i-1}(1-\gamma) \leq \beta_{i} \leq \beta_{i-1}(1+\gamma), \text { for } i \neq 1
$$

where $\gamma$ is a smoothness factor between 0 and 1 , and $i$ is the number of layer.

Since the simulated annealing method explores the entire space of models (inside of a pre-established range of values for each parameter), in order to explore the sensitivity of each parameter, we do not 

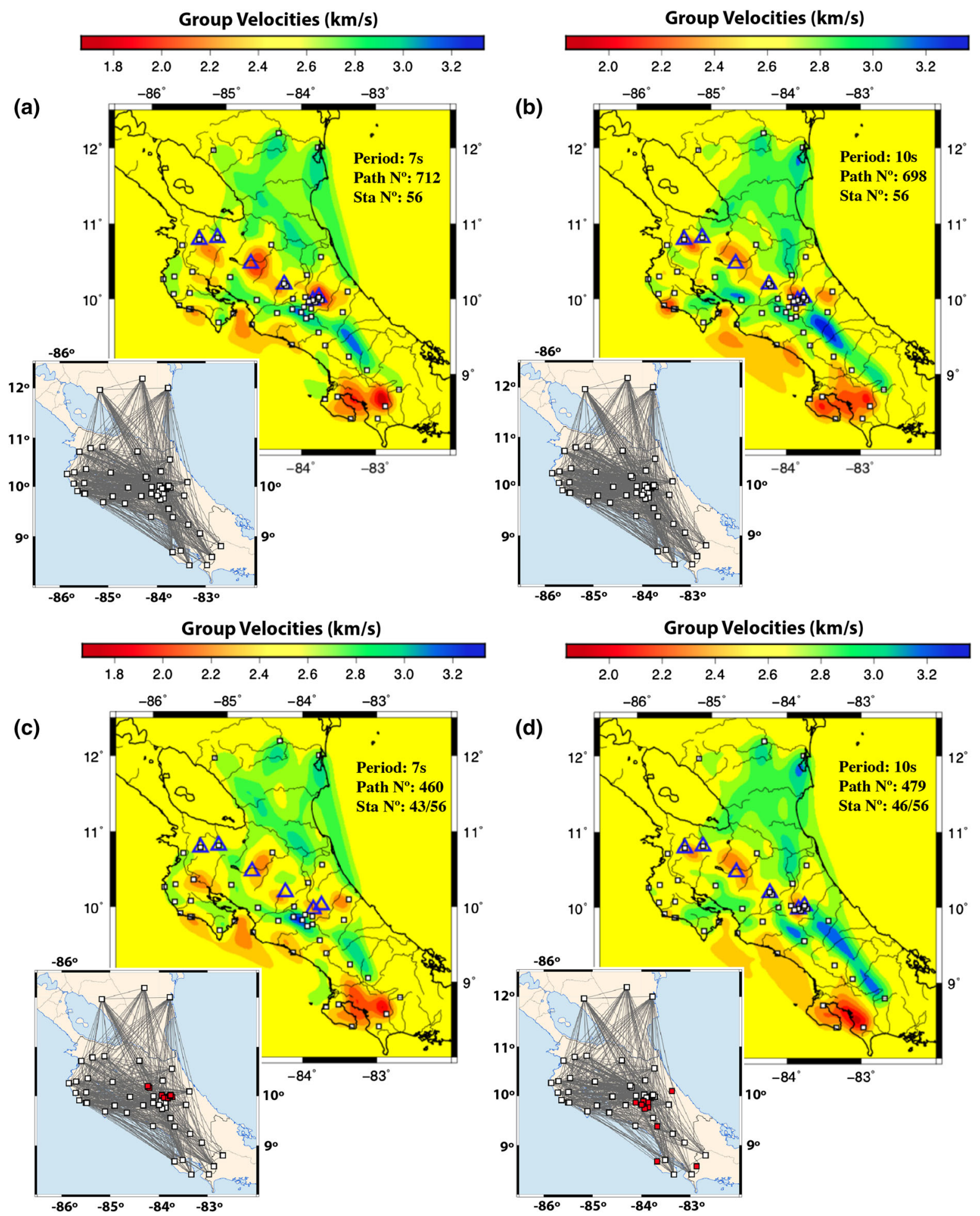

hold only the formally best model, but also all alternative models with normalized L2 below a chosen threshold. This set of models has been inspected

visually to rule out the presence of incompatible models, that may result from instability of the inverse problem. To assure the quality of results, we invert 
Figure 9

Field data group velocity inversion results using subsidiary data sets to assess the robustness of velocity anomalies. Group-velocity maps for periods of $7 \mathrm{~s} \mathrm{(a),} 10 \mathrm{~s}$ (b). c Inversion result for $7 \mathrm{~s}$ period where we removed volcanic stations (red symbols in the ray path coverage figure). The number of stations and station pairs reduced from 56 to 42 and 712 to 460 . d Inversion result for $10 \mathrm{~s}$ period after removal of 9 stations from the Cordillera de Talamanca (CTA) and to the south of Costa Rica

only the dispersion curves that are contained within the area of ray coverage and combine all 1-D velocity-depth models into the final 3-D shear velocity model.

\subsection{D Shear-Wave Velocity Depth Model}

In the Figs. 10 and 11, we show horizontal slices and depth profiles through our final 3D shear-wave velocity model. The same major features are displayed as in the group-velocity maps (Fig. 7). The principal anomalies correlate with the different geological domains, the locations of volcanism, mountain ranges and plains, among others (Fig. 1). For instance, the volcanic arc with its northwestsoutheast trend is visible down to $5 \mathrm{~km}$ depth, with velocities lower than mean velocity. Specifically, these anomalies are strongest beneath the TurrialbaIrazu, Arenal, and Rincon de la Vieja volcanoes as can be seen from the shear-velocity map (Fig. 7a, b, c) and in the depth profiles $\mathrm{B}-\mathrm{B}^{\prime}$ and $\mathrm{C}-\mathrm{C}^{\prime}$ (Fig. 8b, c).

Another important low-velocity anomaly is imaged at the Pacific coast. The shear-wave velocity maps (Fig. 10) and in the depth profiles A-A', B-B' and $C^{\prime}-C^{\prime \prime}$ (Fig. 11) show this anomaly down to $9 \mathrm{~km}$ depth, that can be related to the subduction of the Cocos Plate. The low forearc velocities on top of the plate contact point to an origin due to fluid release from the down going plate (Vannucchi et al. 2001).
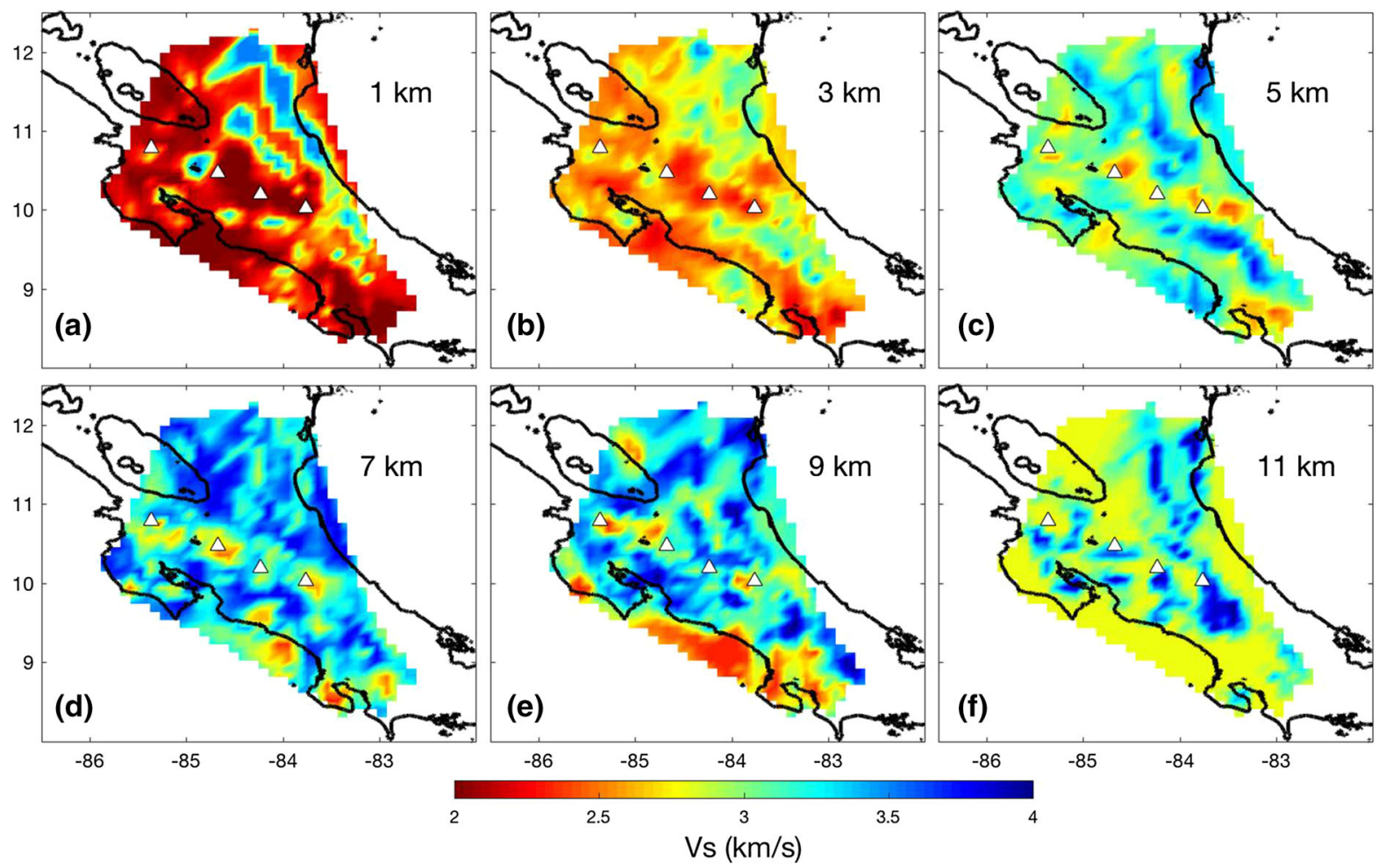

Figure 10

Shear-velocity maps at depth of $1 \mathrm{~km}(\mathbf{a}), 3 \mathrm{~km}(\mathbf{b}), 5 \mathrm{~km}(\mathbf{c}), 7 \mathrm{~km}(\mathbf{d}), 9 \mathrm{~km}(\mathbf{e})$ and $11 \mathrm{~km}(\mathbf{f})$. The white triangles mark principle active volcanoes 
(a) $\mathrm{A}$
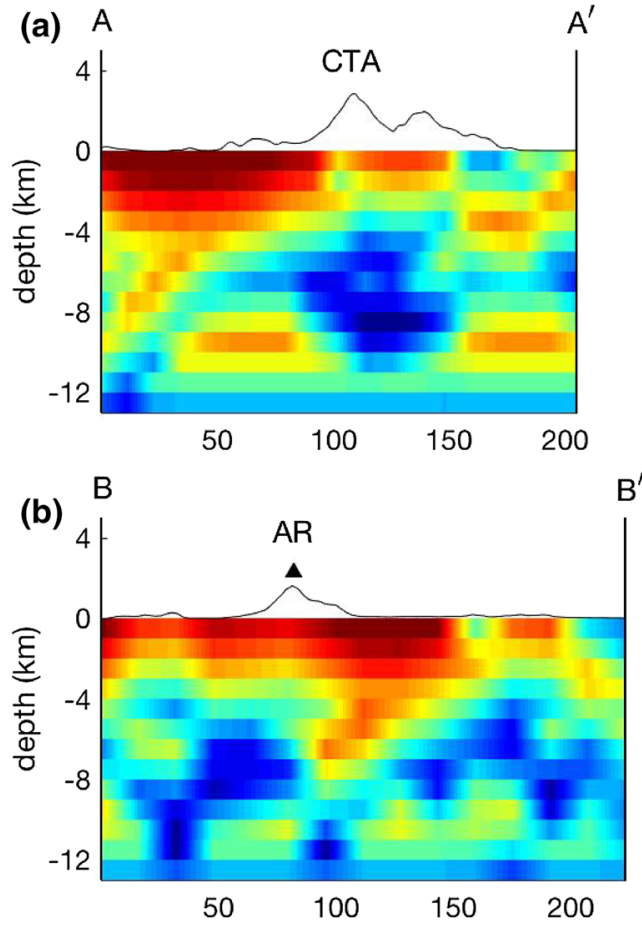

(d) $86^{\circ} \mathrm{W} \quad 84^{\circ} \mathrm{W} \quad 82^{\circ} \mathrm{W}$
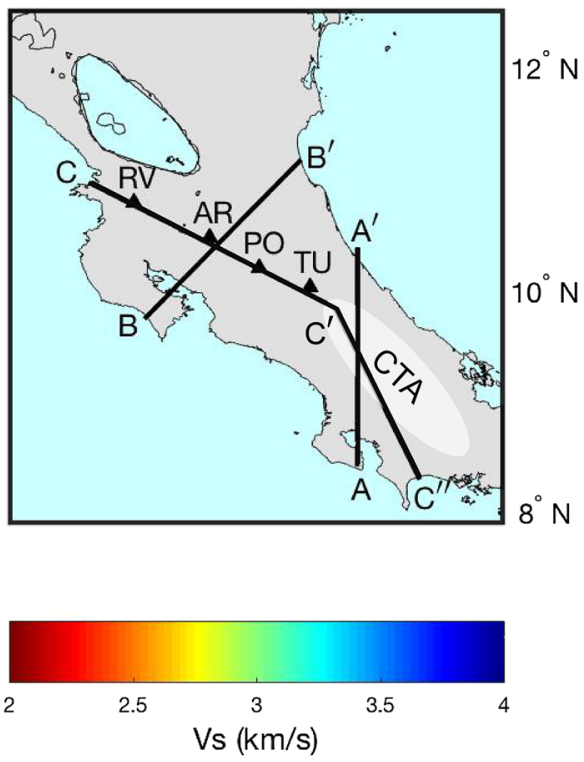

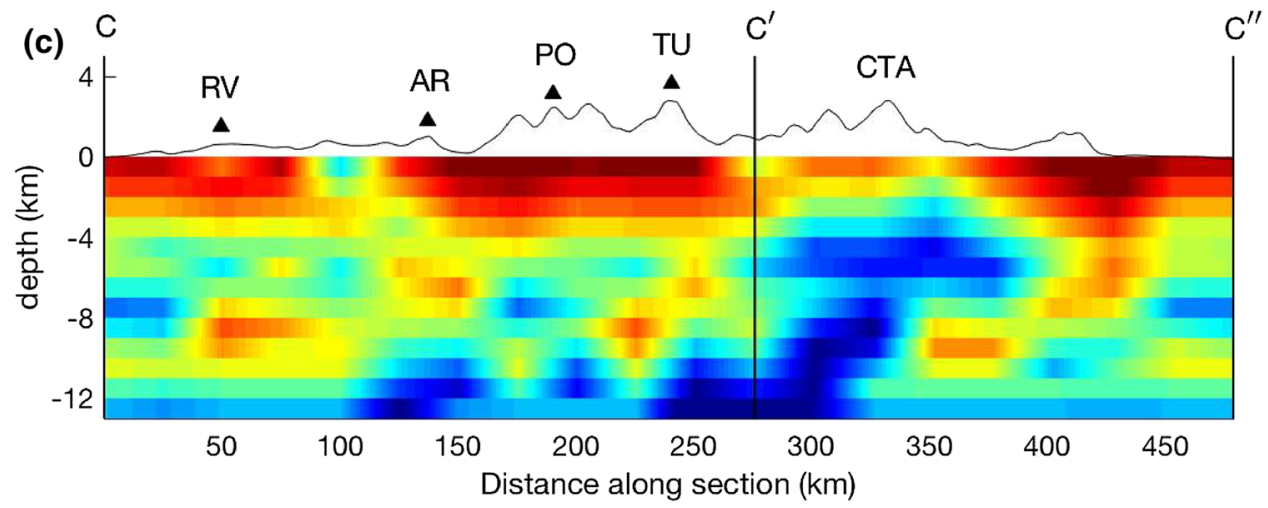

Figure 11

Vertical cross-sections through the shear-wave velocity model: (a) A-A', (b) B-B', (c) C-C'-C $\mathrm{C}^{\prime \prime}$ (d) Costa Rica's map with the cross-sections. The black triangles mark the volcano locations. CTA stands for Cordillera de Talamanca and the volcanoes are: $R V$ Rincón de la Vieja, $A R$ Arenal, $P O$ Poas, $T U$ Turrialba

Variations in intensity of this anomaly along the Pacific margin agree with the pattern in the group velocity distribution (Fig. 7).

The Talamanca Mountain Range is imaged as a prominent high-velocity anomaly over the entire depth range of the inversion model, as seen in the profiles $\mathrm{A}-\mathrm{A}^{\prime}$ and $\mathrm{C}^{\prime}-\mathrm{C}^{\prime \prime}$ (Fig. 11a, c) and in all the shear-velocity maps (Fig. 10). This geological structure was part of the volcanic arc but remains inactive since the onset of subduction of the Cocos ridge, which produced changes in the tectonics (Montero 2001) and in the geochemistry of the region (Hoernle et al. 2008; Gazel et al. 2009, 2011, 2015). North of the volcanic arc we observed a high-velocity anomaly that extends over the entire southeastern part of Nicaragua, similar to the observations made from group-velocity maps (see Sect. 4.3). 


\subsection{Shear-Velocity Depth Resolution}

The resolution of the depth inversion of the measured group velocities at each position is mainly determined by the period range and the corresponding group velocity depth-sensitivity kernels. Figure S5e shows the sensitivity kernels $(\mathrm{T}=5-17 \mathrm{~s}$ ) for $\mathrm{S}$-wave velocity perturbation, while Figs. S5a-d show the test inversions for a positive and negative $\mathrm{S}$-wave velocity perturbation (marked in red) at $8-11 \mathrm{~km}$ depth, respectively. The best recovered model and corresponding dispersion curve are shown in green. Figs. S5a-b, demonstrate that the dispersion curves of the recovered model fully fit the group velocity curve for the input model and that thus both, input and recovered model, explain equally well the input data. Sharp discontinuities can not be resolved by the depth inversion and this explains why the recovered model appears to be a smoothed version of the input model. Nevertheless, the input models are reasonably well retrieved with some depth smearing which is in the order of $\pm 1 \mathrm{~km}$.

\section{Discussion}

\subsection{Volcanic Arc Anomalies}

One of the most prominent features in our groupvelocity maps is a lineament of strong low-velocity anomalies, which follow the volcanic arc in northern and central Costa Rica. The anomalies are observed from the surface down to $\sim 9 \mathrm{~km}$ depth on the profiles B-B', and $\mathrm{C}-\mathrm{C}^{\prime}$ (Fig. 11b, c) and on the horizontal depth slices (Fig. 10a, b, c, d, e). In group velocity maps (Figs. 7, 9 and S2) the low-velocity anomalies can be seen in a broad period range from 5 to $15 \mathrm{~s}$, although the configuration of anomalies is clearest at relatively short periods of $7 \mathrm{~s}-8 \mathrm{~s}$, where three principal anomalies can be distinguished beneath the arc. The absolute $V_{s}$ velocities range from 2.0 to $2.5 \mathrm{~km} / \mathrm{s}$. These anomalies match well with the locations of the six volcanoes that were active over the last 100 years and should be associated with active volcanism. Low velocities in the volcanic arc may be attributed to temperature anomalies and high fluid content, associated to deep hydrothermal systems, magma chambers, and their feeding systems (Dzierma et al. 2010; Lücke et al. 2010).

The volcanic arc has been imaged before by local P-wave earthquake tomography (Husen et al. 2003; Arroyo et al. 2009) and our group velocity maps as well as 3D shear wave model confirm their arcrelated lateral distribution of anomalies. Similar anomalies are also shown by Harmon et al. (2008) in their phase velocity map for $\mathrm{T}=10 \mathrm{~s}$ period. Their analysis covers mainly the Pacific coast of Nicaragua and Costa Rica north of $10^{\circ} \mathrm{N}$. In P-wave earthquake tomography (Husen et al. 2003; Arroyo et al. 2009), albeit variable resolution, the arc-related anomalies are visible down to about $30 \mathrm{~km}$. Note that we observe the volcanic arc related anomalies with slightly different geometry and amplitudes, which we mostly attribute to data variability. The depth extend of our inversion is restricted by the used frequencies to the upper $15 \mathrm{~km}$ of the crust and we can thus not confirm the presence of arc-related anomalies down to about $30 \mathrm{~km}$ as postulated in Husen et al. (2003).

At the southeasternmost edge of the volcanic arc a low-velocity anomaly is located beneath the Turrialba-Irazu volcanoes, clearly visible in group velocity maps over the full-analysed period range from $5 \mathrm{~s}$ up to $17 \mathrm{~s}$, and in the 3D model until depths of $10 \mathrm{~km}$. Our results agree with receiver function studies (Dzierma et al. 2010), that identify the low-velocity anomaly beneath the Turrialba-Irazu volcanoes, and interpret it as a larger magma chamber or feeding system, which in turn coincides with a gravimetric low observed by (Lücke et al. 2010). Lücke et al. (2010) interpreted this anomaly as a joint magma reservoir that feeds the Turrialba-Irazu system. Within the current resolution limits, our results support this view.

At the Arenal and Poas volcanoes, the anomaly appears weaker at long periods, and the low-velocity structures vanish at $5 \mathrm{~km}$ depth beneath Poas, while they remain stable until $9 \mathrm{~km}$ depth beneath Arenal. The depth inversions (Figs. 10a-e, 11b, c) suggest that the feeding system of Arenal is deeper than for Poas, but it may also indicate that this volcanic system is mainly fed from beneath the Arenal volcano at deeper depths. At periods longer than $10 \mathrm{~s}$ and at depths below $5 \mathrm{~km}$, the Arenal-Poas 
anomaly is difficult to identify in the images, suggesting that the deep rooted feeding system may be less developed than for the Turrialba-Irazu and Rincon de la Vieja-Miravalles volcanic systems.

The northernmost low-velocity anomaly identified beneath the volcanic arc is located at the Rincon de la Vieja and Miravalles volcanoes, thus completing the list of recently active volcanoes related to a crustal scale signature of fluid ascent. Husen et al. (2003) detected a low-velocity anomaly, although they report it to be not very reliable due to poor resolution. Ambient noise tomography shows a more homogeneous ray path coverage and good resolution in this area, and clearly confirms the presence of this anomaly over a period band from 7 to $17 \mathrm{~s}$ (Figs. 7 and S2). Following profile $\mathrm{C}-\mathrm{C}^{\prime}$ (Fig. 8c) and the shear-wave velocity maps (Fig. 10a-e) the feeding system is observed from the surface down to $9 \mathrm{~km}$ depth. Still, this anomaly is located close to the edge of the network, and must be reconstructed from relatively long ray paths. Hence the imaging is affected by the removal of individual stations (Fig. 9a).

\subsection{Pacific Coast (Subduction Zone)}

The Pacific coast of Costa Rica is marked by the subduction of the Cocos plate underneath the Caribbean and Panama plate along the MAT. Our group velocity maps as well as the 3D shear-wave velocity model show lower-than-average velocities in the Pacific coast (Figs. 10 and 11). The anomalies seem to be strongest and most continuous at periods between 10 and $17 \mathrm{~s}$ (Figs. 7 and S2). In view of a lack of sediments at the Pacific margin of Costa Rica (e.g. Vannucchi et al. 2001) the low forearc velocities on top of the plate contact point to an origin due to fluid release from the downgoing plate. This hypothesis appears consistent with ongoing fast subduction.

Fluid release is a common process in subduction environments. The palaeo spreading direction of the oceanic crust subducting into the trench in the East Pacific Rise (EPR) is perpendicular to the margin, while the Cocos-Nazca spreanding centre (CNS) is parallel (Fig. 1b). During bending into the trench the EPR crust produces normal faulting parallel to the ridge strike while the CNS crust does not develop a visible faulting pattern (Ranero et al. 2003). Anisotropy studies on the Juan de Fuca ridge indicate that permeability increases parallel to ridge strike compared to the perpendicular direction (Fisher et al. 2008). The anisotropy and normal faulting parallel to the ridge strike could indicate that the EPR crust is more permeable than the CNS crust and may therefore permit high along-strike and low vertical fluid transport into the upper plate. In contrast, fluids in the CNS crust are expected to move along the detachment into the upper plate (Audet and Schwartz 2013). Thus, the low-velocity anomalies observed along the Pacific coast, may be reflecting the fluid release from the underlying plate (the CNS crust) in this particular environment.

Significant along strike variations in seafloor morphology, dip angle and crustal thickness of the subducting plate in front of the trench (Morell 2015) are clearly reproduced by the group velocity distribution (e.g. Figure 8b). Subduction beneath the Nicoya Peninsula is associated with relatively high velocities, in contrast with significantly lower velocities associated with subduction of the Cocos Ridge beneath the Osa Peninsula and intermediate velocities associated with subduction of the seamount segment at the central Pacific margin. This variability may be plausibly related to increasing fluid release from the subducting plate from northwest to southeast. Previously, Audet and Schwartz (2013) performed a waveform inversion of receiver functions and estimate the $\mathrm{P}-\mathrm{S}$ velocity ratio (or $\mathrm{V}_{\mathrm{p}} / \mathrm{V}_{\mathrm{s}}$ ) for the Nicoya Peninsula. Their results show a higher ratio in the southeast $\left(\mathrm{V}_{\mathrm{p}} / \mathrm{V}_{\mathrm{s}}=2.6 \pm 0.2\right)$ compared with the northwest $\left(\mathrm{V}_{\mathrm{p}} / \mathrm{V}_{\mathrm{s}}=2.3 \pm 0.3\right)$ in the forearc crust. The higher $\mathrm{V}_{\mathrm{p}} / \mathrm{V}_{\mathrm{s}}$ ratio to the southeast can be explained by decreased $\mathrm{S}$-wave velocities, which are also observed in our group velocity maps. Further, previous studies (Arroyo et al. 2009; DeShon et al. 2006; Husen et al. 2003; Dinc et al. 2010; Dzierma et al. 2011; Hinz 1996; von Huene 1995; von Huene et al. 2000; Ye et al. 1996) already support the interpretation that the observed low-velocity anomalies are related to the presence of high fluid content within a highly fractured part of the margin wedge, rather than by an accumulation of sediments. 


\subsection{Talamanca Mountain Range}

The Talamanca mountain range corresponds to a strong high-velocity anomaly over the entire analysed period range (see group velocity maps, Figs. 7 and 9) and the entire depth range of the 3D shear-wave velocity model (Figs. 10 and 11). This result indicates an important transition in central Costa Rica, coincident with the termination of the present volcanic arc and the location of the Central Costa Rica Deformed Belt (CCRDB). It also coincides with a change in Moho depth (Dzierma et al. 2010). The mountain range is formed mostly of intrusive and mélange material, and high velocities can be inferred at crustal scale. The presence of high-velocity anomalies beneath the Talamanca range can be deduced directly from the dispersion curves for EGF paths along the strike of the range (blue station paths in Fig. 5). Rayleigh waves in the CTA propagate clearly faster than anywhere else in Costa Rica. The checkerboard and peak models are reconstructed reasonably well, with smearing occurring in the dominant ray path direction parallel to the coast. The removal from the inversion of nine strategically selected stations in central Costa Rica and the Osa peninsula (Fig. 10d) gives further support for the location and amplitude of anomalies in southeastern Costa Rica.

It is expected that extinction of volcanism in the Talamanca range is related to the appearance of the Cocos ridge in the subduction zone in the south of Costa Rica, producing changes in the tectonics (Montero 2001) and geochemistry of the region (Hoernle et al. 2008; Gazel et al. 2009, 2011, 2015) as well as the transference of compression into the overriding plate, causing the growth of the Talamanca range and a compressive tectonic regime in the backarc (Suárez et al. 1995; Morell 2015). Volcanic activity in this part of the arc became extinct in the late Miocene. High velocities are consistent with a lack of fluids, in agreement with a long-term absence of volcanism for about $8 \mathrm{Ma}$ (Morell et al. 2012). The transition between the active and extinct parts of the volcanic arc comes along with a change from an extensional stress regime in the north (volcanic arc) to a high compression regime in the south (CTA) of the central section (Quintero and
Güendel 2000). The high group velocities in this zone may be related to the particular geodynamic setting of the CTA.

\section{Conclusions}

Cross correlation of ambient noise at the seismic broadband network of Costa Rica is able to provide a reasonably homogeneous data coverage for surface wave tomography across the entire country. Despite the proximity to noise sources in the Pacific Ocean as well as the Caribbean Sea, more than 1 year of cross correlations were necessary to achieve robust EGFs over the frequency band from 5 to $17 \mathrm{~s}$, representative for crustal Rayleigh waves. The signal to noise ratio and the convergence of EGFs improves clearly by using a phase-weighted stack (tf-PWS), compared to a linear stack. Average curves are in agreement with predictions from established 1-D Earth models for Costa Rica, while the variability of dispersion curves follows consistent regional patterns, and measured curves clearly cluster within the individual geological units. Ambient noise tomography permitted to obtain stable and consistent group velocity maps. Subsequent 3D inversion confirm the interpretation of the group velocity maps. Our results improve the characterization of the shallow crust in the study area, allowing to determine the depth distribution of velocity anomalies and contributing to our understanding of crustal structure, volcanism and subduction characteristics along the margin.

Tomographic images evidence a large variability of shear wave speed in the Costa Rican crust. We expect that this variability is mainly related due to the presence of fluids in the Costa Rican subduction system. Low-velocity anomalies are found along the volcanic Arc, in agreement with the places of recent eruption activity (Rincón de la Vieja-Miravalles, Arenal-Poás and Turrialba-Irazú). Anomalies along the Pacific coast suggest fluid release from the subducting Cocos plate into the forearc crust. The coastal anomaly, within the limitations imposed by inferior ray path coverage at the edge of the network, appears to reproduce the well-known along-strike changes in the Cocos plate lithosphere, from the EPR crust subducting beneath the Nicoya Peninsula to the 
Cocos ridge, which is formed in the CNS crust and subducted beneath the Osa Peninsula. In turn, the Cocos ridge subduction could be the cause of the high-velocity anomalies beneath the Talamanca Mountain Range that constitutes the extinct, southeastern sector of the volcanic arc.

\section{Acknowledgements}

The authors want to express their gratitude to the Observatiorio Vulcanológico y Sismológico de Costa Rica-Universidad Nacional de Costa Rica (OVSICORI-UNA) and the Incorporated Research Institutions for Seismology (IRIS) for provididing the data of this study. We received support from Mineco/Feder Project CGL2015-67130-C2-2-R, Junta de Andalucía research group RNM 104, and CGL2013-48601-C2-1-R (MISTERIOS). This study benefitted greatly from networking within the EUfunded COST action ES1401 TIDES (TIme DEpendent Seismology). In particular E.N. acknowledges to Universidad Nacional de Costa Rica (UNA) for the scholarship to complete her Ph.D. (grant number A-JB-002-2012). We also thank to Laura Becerril for her help with the Geology Map of Costa Rica. Editor and referees are acknowledged for their carefull and constructive reviews and all efforts involved with handling this manuscript.

Publisher's Note Springer Nature remains neutral with regard to jurisdictional claims in published maps and institutional affiliations.

\section{REFERENCES}

Alfaro, A., Denyer, P., Alvarado, G. E., Gazel, E., \& Chamorro, C. (2018). Stratigraphy and petrography of igneous rocks in the Cordillera de Talamanca, Costa Rica. Geological Magazine of Central America, 58, 7-36. https://doi.org/10.15517/rgac.v58i0. 32669

Arroyo, I. G., Husen, S., Flueh, E. R., Gossler, J., Kissling, E., \& Alvarado, G. E. (2009). Three-dimensional P-wave velocity structure on the shallow part of the Central Costa Rican Pacific margin from local earthquake tomography using off- and onshore networks. Geophysical Journal International, 179(2), 827-849. https://doi.org/10.1111/j.1365-246X.2009.04342.x.
Audet, P., \& Schwartz, S. (2013). Hydrologic control of forearc strength and seismicity in the Costa Rican subduction zone. Nature Geoscience, 6(10), 852-855. https://doi.org/10.1038/ ngeo1927.

Barckhausen, U., Ranero, C., von Huene, R., Cande, S. C., \& Roeser, H. A. (2001). Revised tectonic boundaries in the cocos plate off Costa Rica: implications for the segmentation of the convergent margin and for plate tectonic models. Journal of Geophysical Research, 106(19), 207-220.

Berteussen, K. A. (1977). Moho depth determination based on spectral ratio analysis of NORSAR long-period $\mathrm{P}$ waves. Physics of the Earth and Planetary Interiors, 31, 313-326.

Bilek, S. L., Schwartz, S. Y., \& DeShon, H. R. (2003). Control of seafloor roughness on earthquake rupture behavior. Geology, 31, 455-458.

Bunduschuh, J., \& Alvarado, G. E. (2007). Central America: Geology resources, hazards (Vol. 1, p. 663). London: Taylor \& Francis.

Carr, M. J. (1984). Symmetrical and segmented variation of physical and geochemical characteristics of the Central American volcanic front. Journal of Volcanology and Geothermal Research, 20, 231-252.

DeMets, C., Gordon, R. G., \& Argus, D. F. (2010). Geologically current plate motions. Geophysical Journal International, 181, 1-80. https://doi.org/10.1111/j.1365-246x.2009.04491.x.

DeShon, H. R. (2003). Seismogenic zone structure of the southern Middle America Trench, Costa Rica. Journal of Geophysical Research, 108(B10), 2491. https://doi.org/10.1029/ $2002 J B 002294$.

DeShon, H. R., Schwartz, S. Y., Newman, A. V., González, V., Protti, M., Dorman, L. M., et al. (2006). Seismogenic zone structure beneath the Nicoya Peninsula, Costa Rica, from threedimensional local earthquake P- and S-wave tomography. Geophysical Journal International, 164(1), 109-124. https://doi.org/ 10.1111/j.1365-246X.2005.02809.x.

Dinc, A. N., Koulakov, I., Thorwart, M., Rabbel, W., Flueh, E. R., Arroyo, I., et al. (2010). Local earthquake tomography of central Costa Rica: transition from seamount to ridge subduction. Geophysical Journal International, 183(1), 286-302. https://doi.org/ 10.1111/j.1365-246X.2010.04717.x.

Dzierma, Y., Rabbel, W., Thorwart, M. M., Flueh, E. R., Mora, M. M., \& Alvarado, G. E. (2011). The steeply subducting edge of the Cocos Ridge: Evidence from receiver functions beneath the northern Talamanca Range, south-central Costa Rica. Geochemistry, Geophysics, Geosystems, 12, Q04S30. https://doi.org/ 10.1029/2010GC003477.

Dzierma, Y., Thorwart, M. M., Rabbel, W., Flueh, E. R., Alvarado, G. E., \& Mora, M. M. (2010). Imaging crustal structure in south central Costa Rica with receiver functions. Geochemistry, Geophysics, Geosystems, 11, Q08S26. https://doi.org/10.1029/ 2009GC002936.

Ekström, G., Nettles, M., \& Dziewonski, A. M. (2012). The global CMT project 2004-2010: centroid-moment tensors for 13,017 earthquakes. Physics of the Earth and Planetary Interiors, 200-201, 1-9. https://doi.org/10.1016/j.pepi.2012.04.002.

Fan, G. W., Beck, S. L., \& Wallace, T. C. (1993). The seismic source parameters of the 1991 Costa Rica aftershock sequence: Evidence for a transcurrent plate boundary. Journal of Geophysical Research, 98, 15759-15778. https://doi.org/10.1029/ 93JB01557. 
Fisher, A. T., Davis, E. E., \& Becker, K. (2008). Borehole-toborehole hydrologic response across $2.4 \mathrm{~km}$ in the upper oceanic crust: Implications for crustal-scale properties. Journal of Geophysical Research, 113(B7), 3109-3115. https://doi.org/10.1029/ $2007 J B 005447$.

Gazel, E., Carr, M. J., Hoernle, K., Feigenson, M. D., Szymansky, D., Hauff, F., et al. (2009). Galapagos-OIB signature in southern Central America: Mantle refertilization by arc-hot spot interaction. Geochemistry, Geophysics and Geosystems. https://doi.org/ 10.1029/2008GC002246.

Gazel, E., Hayes, J., Hoernle, K., Kelemen, P., Everson, E., Holbrook, W. S., et al. (2015). Continental crust generated in oceanic arcs. Nature Geosciences. https://doi.org/10.1038/NGEO2392.

Gazel, E., Hoernle, K., Carr, M. J., Herzberg, C., Saginor, I., van den Boogard, P., et al. (2011). Plume-subduction interaction in southern Central America: Mantle upwelling and slab melting. Lithos, 121, 171-134.

Global Volcanism Program, 2013. Volcanoes of the world, v. 4.6.7. Venzke, E (ed.). Smithsonian Institution. Downloaded 23 Mar 2018. https://dx.doi.org/10.5479/si.GVP.VOTW4-2013

Goes, S. D. B., Velasco, A. A., Schwartz, S., \& Lay, T. (1993). The April 22, 1991, Valle de la Estrella, Costa Rica $(\mathrm{Mw}=7.7)$ earthquake and its tectonic implications: A board-band seismic study. Journal of Geophysical Research, 98, 8127-8142.

Gouédard, P., Roux, P., Campillo, M., \& Verdel, A. (2008). Convergence of the two-point correlation function toward the Green's function in the context of a seismic-prospecting data set. Geophysics, 73(6), V47-V53. https://doi.org/10.1190/1.2985822.

Haned, A., Stutzmann, E., Schimmel, M., Kiselev, S., Davaille, A., \& Yelles-Chaouche, A. (2015). Global tomography using seismic hum. Geophysical Journal International, 204(2), 1222-1236. https://doi.org/10.1093/gji/ggv516.

Harmon, N., Gerstoft, P., Rychert, C. A., Abers, G. A., Salas de la Cruz, M., \& Fischer, K. M. (2008). Phase velocities from seismic noise using beamforming and cross correlation in Costa Rica and Nicaragua. Geophysical Research Letters, 35(19), 10-16. https:// doi.org/10.1029/2008GL035387.

Herrmann, R. B. (2013). Computer programs in seismology: an evolving tool for instruction and research. Seismological Research Letters, 84, 1081-1088. https://doi.org/10.1785/ 0220110096.

Hinz, K. (1996). Tectonic structure of the convergent Pacific margin offshore Costa Rica from multichannel seismic reflection data. Tectonics, 15, 54.

Hoernle, K., Abt, D. L., Fischer, K. M., Nichols, H., Hauff, F., Abers, G. A., et al. (2008). Arc-parallel flow in the mantle wedge beneath Costa Rica and Nicaragua. Nature, 451, 1094-1097. https://doi.org/10.1038/nature06550.

Husen, S., Quintero, R., Kissling, E., \& Hacker, B. (2003). Subduction-zone structure and magmatic processes beneath Costa Rica constrained by local earthquake tomography and petrological modelling. Geophysical Journal International, 155, 11-32.

Iglesias, A., Cruz-Atienza, V. M., Shapiro, N. M., Singh, S. K., \& Pacheco, J. F. (2001). Crustal Structure of South-central Mexico estimated from the inversion of surface-wave dispersion curves using genetic and simulated annealing algorithms. Geofísica Internacional, 40-3, 181-190.

Incorporated Research Institutions for Seismology (IRIS). Downloaded 15 Jan 2016. http://ds.iris.edu/ds/
Jordan, T. H. (1975). The present-day motions of the Caribbean Plate. Journal of Geophysical Research, 80(32), 4433-4439. https://doi.org/10.1029/jb080i032p04433.

Lecocq, T., Caudron, C., \& Brenguier, F. (2014). MSNoise, a python package for monitoring seismic velocity changes using ambient seismic noise. Seismological Research Letters, 85(3), 715-726. https://doi.org/10.1785/0220130073.

Lücke, O. H., Götze, H.-J., \& Alvarado, G. (2010). A constrained 3D density model of the upper crust from gravity data interpretation for Central Costa Rica. International Journal of Geophysics, 2010(b1), 1-9. https://doi.org/10.1155/2010/ 860902.

Marshall, J. S., Fisher, D. M., \& Gardner, Y. T. W. (2000). Central Costa Rica deformed belt: kinematics of diffuse faulting across the western Panama block. Tectonics, 19(3), 468-492.

Montero, W. (2001). Neotectónica de la region central de Costa Rica: Frontera oeste de la microplaca de Panamá. Revista Geológica de América Central, 24, 29-56.

Morell, K. D. (2015). Late Miocene to recent plate tectonic history of the southern Central America convergent margin. Geochemistry, Geophysics, Geosystems, 16(10), 3362-3382. https://doi. org/10.1002/2015GC005971X.

Morell, K. D., Kirby, E., Fisher, D. M., \& van Soest, M. (2012). Geomorphic and exhumational response of the Central American Volcanic Arc to Cocos Ridge subduction. Journal of Geophysical Research: Solid Earth, 117, B04S409. https://doi.org/10.1029/ 2011JB008969.

Poveda, E., Julià, J., Schimmel, M., \& Perez-Garcia, N. (2018). Upper and middle crustal velocity structure of the colombian andes from ambient noise tomography: investigating SubductionRelated Magmatism in the Overriding Plate. Journal of Geophysical Research, 123(2), 1459-1485. https://doi.org/10.1002/ 2017 JB014688.

Protti, M., Guendel, F., \& Malavassi, E. (2001). Evaluación del potencial sísmico de la Península de Nicoya ( $1^{\mathrm{a}}$ ed., p. 144). Heredia, Costa Rica: Editorial Fundación Universidad Nacional.

Protti, M., Güendel, F., \& McNally, K. (1994). The geometry of the Wadati-Benioff zone under southern Central America and its tectonic significance: results from a high-resolution local seismographic network. Physics of the Earth and Planetary Interiors, 84, 271-287.

Protti, M., McNally, K., Pacheco, J. F., Gonzalez, V., Montero, C., Segura, J., et al. (1995). The March 25, 1990 (Mw = 7.0, ML = 6.8), earthquake at the entrance of the Nicoya Gulf, Costa Rica: its prior activity, foreshocks, aftershocks, and triggered seismicity. Journal of Geophysical Research, 100(B10), 20345-20358.

Quintero, R., \& Güendel, F. (2000). Stress field in Costa Rica, Central America. Journal of Seismology, 4, 297-319.

Quintero, R., \& Kissling, E. (2001). An improved P-wave velocity reference model for Costa Rica. Geofisica Internacional, 40(1), 3-19.

Ranero, C. R., Morgan, J. P., McIntosh, K., \& Reichert, C. (2003). Bending-related faulting and mantle serpentinization at the Middle America trench. Nature, 425, 367-373.

Rawlinson, N. (2005). FMST: Fast Marching surface tomography package, research school of earth sciences, Australian National University, Canberra ACT 0200

Rawlinson, N., Reading, A. M., \& Kennett, B. L. N. (2006). Lithospheric structure of Tasmania from a novel form of 
teleseismic tomography. Journal of Geophysical Research, 111, B02301. https://doi.org/10.1029/2005jb003803.

Rawlinson, N., \& Sambridge, M. (2004). Wave front evolution in strongly heterogeneous layered media using the fast marching method. Geophysical Journal International, 156(3), 631-647. https://doi.org/10.1111/j.1365-246X.2004.02153.x.

Sallarès, V., Charvis, P., Flueh, E. R., \& Bialas, J. (2003). Seismic structure of Cocos and Malpelo Volcanic Ridges and implications for hot spot-ridge interaction. Journal of Geophysical Research, 108(B12), 2564. https://doi.org/10.1029/2003jb 002431.

Schimmel, M., \& Gallart, J. (2007). Frequency-dependent phase coherence for noise suppression in seismic array data. Journal of Geophysical Research, 112(B4), 13,656-13714. https://doi.org/ 10.1029/2006JB004680.

Schimmel, M., \& Paulssen, H. (1997). Noise reduction and detection of weak, coherent signals through phase-weighted stacks. Geophysical Journal International, 130, 497-505. https:// doi.org/10.1111/j.1365-246X.1997.tb05664.x.

Schimmel, M., Stutzmann, E., \& Gallart, J. (2011). Using instantaneous phase coherence for signal extraction from ambient noise data at a local to a global scale. Geophysical Journal International, 184(1), 494-506. https://doi.org/10.1111/j.1365-.

Schimmel, M., Stutzmann, E., \& Ventosa, S. (2017). Measuring group velocity in seismic noise correlation studies based on phase coherence and resampling strategies. IEEE Transactions on Geoscience and Remote Sensing, 55(4), 1928-1935. https:// doi.org/10.1109/TGRS.2016.2631445.

Sethian, J. A. (1996). A fast maching level set method for monotonically advancing fronts. Proceedings of the National Academy of Sciences, 93, 1591-1595.

Sethian, J. A. (1999). Level set methods and fast marching methods: Evolving interfaces in computational geometry, fluid mechanics, computer vision and materials sciences (2nd ed.). Cambridge, MA: Cambridge Univ. Press.

Sethian, J. A. (2001). Evolution, implementation, and application of level set and fast marching methods for advancing fronts. Journal of Computational Physics, 169(2), 503-555. https://doi. org/10.1006/jcph.2000.665.

Silver, E., Reed, D., Tagudin, J., \& Heil, D. (1990). Implications of the North and South Panama thrut belts for the origin of the panama orocline. Tectonics, 9(2), 261-281. https://doi.org/10. 1029/tc009i002p00261.

Stefan, J. F., Blanchet, R., \& Mercier De Lepinay, B. (1988). Northern and southern Caribbean festoons (Panama, Colombia-
Venezuela and Hispaniola-Puerto Rico), interpreted as pseudosubductions induced by the East-West shortening or the pericaribbean continental frame. In F. C. Wezel (Ed.), Developments in geotectonics 21, the origin of arcs (p. 530). Amsterdam: Elsevier.

Stockwell, R. G., Mansinha, L., \& Lowe, R. P. (1996). Localization of the Complex Spectrum: the S Transform. IEEE Transactions on Signal Processing, 44(4), 998-1001.

Suárez, G., Pardo, M., Domínguez, J., Ponce, L., Montero, W., Boschini, I., et al. (1995). The Limón, Costa Rica earthquake of April 22, 1991: back arc thrusting and collisional tectonics in a subduction environment. Tectonics, 14(2), 518-530. https://doi. org/10.1029/94tc02546.

Tournon, J., \& Alvarado, G. (1997). Carte géologique du Costa Rica-mapa geológico de Costa Rica. Notice Explicative-Folleto Explicativo, escala, 1, 500.000. (80).

Vannucchi, P., Scholl, D. W., Meschede, M., \& McDouglas-Reid, K. (2001). Tectonic erosion and consequent collapse of the Pacific margin of Costa Rica: combined implications form ODP Leg 170, of Nicoya Peninsula. Tectonics, 20(5), 649-668.

Ventosa, S., Schimmel, M., \& Stutzmann, E. (2017). Extracting surface waves, hum and normal modes: time-scale phaseweighted stack and beyond. Geophysical Journal International, 211(1), 30-44. https://doi.org/10.1093/gji/ggx284.

von Huene, R. E. A. (1995). Morphotectonics of the Pacific convergent margin of Costa Rica. Geological Society of America Special Paper, 295, 291-307.

von Huene, R., Ranero, C. R., Weinrebe, W., \& Hinz, K. (2000). Quaternary convergent margin tectonics of Costa Rica, segmentation of the Cocos Plate, and Central American volcanism. Tectonics, 19, 314-334.

Wang, K., \& Bilek, S. L. (2014). Invited review paper: Fault creep caused by subduction of rough seafloor relief. Tectonophysics, 610, 1-24. https://doi.org/10.1016/j.tecto.2013.11.024.

Werner, R., Hoernle, K., van den Bogaard, P., Ranero, C., von Huene, R., \& Korich, D. (1999). Drowned 14-m.y.-old Galápagos archipelago off the coast of Costa Rica: Implications for tectonic and evolutionary models. Geology, 27(6), 499-505. https://doi.org/10.1130/0091-7613(1999)027<0499:DMYOGP> 2.3.CO;2.

Ye, S., Bialas, J., Flueh, E. R., Stavenhagen, A., \& von Huene, R. (1996). Crustal structure of the Middle American Trench off Costa Rica from wide-angle seismic data. Tectonics, 15, 1006-1021. 